\title{
Seasonal changes in the North Atlantic cold anomaly: the influence of cold surface waters from coastal Greenland and warming trends associated with variations in subarctic sea ice cover
}

Article

Accepted Version

Allan, D. and Allan, R. P. (2020) Seasonal changes in the North Atlantic cold anomaly: the influence of cold surface waters from coastal Greenland and warming trends associated with variations in subarctic sea ice cover. Journal of Geophysical Research: Oceans, 124 (12). pp. 9040-9052. ISSN 2169-9275 doi: https://doi.org/10.1029/2019JC015379 Available at https://centaur.reading.ac.uk/87865/

It is advisable to refer to the publisher's version if you intend to cite from the work. See Guidance on citing.

To link to this article DOI: http://dx.doi.org/10.1029/2019JC015379

Publisher: Wiley

All outputs in CentAUR are protected by Intellectual Property Rights law, including copyright law. Copyright and IPR is retained by the creators or other copyright holders. Terms and conditions for use of this material are defined in the End User Agreement. 


\section{www.reading.ac.uk/centaur}

\section{CentAUR}

Central Archive at the University of Reading

Reading's research outputs online 
1 Seasonal changes in the North Atlantic cold anomaly: the influence of cold surface waters from coastal

2 Greenland and warming trends associated with variations in subarctic sea ice cover.

3 Authors: David Allan (unaffiliated) and Richard P. Allan, Department of Meteorology and National Centre for 4 Earth Observations, University of Reading, Reading, Berkshire, RG6 6CB, UK

5 Key Points:

6

- The North Atlantic cold anomaly is most intense in February when maximum absolute cooling since 1900 is almost $0.9^{\circ} \mathrm{C}$ at $53^{\circ} \mathrm{N} 36^{\circ} \mathrm{W}$.

- Winter intensification of the cold anomaly is linked to late autumn cooling of surface waters near the coast of SE Greenland.

- Summer attenuation of the cold anomaly is linked to changes in sea ice cover which contribute to Arctic temperature amplification. 


\section{Abstract}

Worldwide sea surface temperatures (SST) have increased on average by about $1{ }^{\circ} \mathrm{C}$ since 1900 with the exception of a region of the North Atlantic subpolar gyre (SPG) near $50^{\circ} \mathrm{N}$ which has cooled by up to $0.9^{\circ} \mathrm{C}$ over the same period, generating the negative feature on temperature anomaly maps which has been colloquially described by Rahmstorf et al. (2015) as the 'cold blob' (abbreviated here CB). This unique long term surface cooling trend is most evident in February but in August net warming is observed even at CB epicentre and the $\mathrm{CB}$ itself is reduced to a mere 'warming hole'. These seasonal changes in the intensity of the CB are the product of two separate factors: (1) a long term winter cooling specific for the CB region which appears to be associated with cooling of Greenland coastal waters in autumn, plausibly linked to summer meltwater from icebergs and sea ice and (2) summer warming effects which derive from (a) dramatic reductions in summer sea ice cover in the sub-Arctic over the last 30 years that allows enhanced absorption of sunlight by the new open water in summer and (b) an unusual period of increased summer sub-Arctic ice cover in the early $20^{\text {th }}$ century which lowers the SST baseline measured from 1900, thus increasing the calculated linear rate of change of SST with time. Both of these effects could contribute to the observed Arctic amplification of warming.

\section{Plain language summary}

In a world which has notably warmed by about $1^{\circ} \mathrm{C}$ over the last 100 years, the 'cold blob' represents a unique ocean surface region in the central North Atlantic which paradoxically has cooled by almost $1{ }^{\circ} \mathrm{C}$ over the same period. We show here that the intensity and coherence of the cold blob is greatest in winter but its development appears to be connected with a surface cooling of water near the SE coast of Greenland in late autumn. This pool of cold water is likely to be related to summer meltwater from the Greenland ice sheet and sea and we suggest ways in which it could reach and sustain the cold blob. In summer the cold blob disappears because it is overwhelmed by warming influences associated with past and current reductions in sea ice cover in the coastal sub-Arctic regions of the NW Atlantic. These warming influences associated with reductions in sea ice are part of the reason why Arctic temperatures have recently risen faster than anywhere else.

\section{Introduction}

Sea surface temperature (SST) grid-referenced across the North Atlantic Ocean is of particular significance because it represents a key component of the world climate system (Trenberth et al. 2007) which influences weather patterns across Europe and N. America (Ossó et al. 2017). SST is determined by a complex array of factors because it depends not only on insolation and heat exchange between ocean and atmosphere but also on the degree of surface stratification and the interplay of ocean currents. Thus grid-referenced SST observations can monitor fluctuations in the major ocean currents that transport warm surface waters from the south and cold waters from the north around the NW Atlantic subpolar gyre (SPG, Fig 1). These currents are integral components of the Atlantic Meridional Overturning Circulation (AMOC) which is thought to influence the climate of Europe and North America (Duchez et al 2016; Simmonds 2018; Josey et al 2018; Caesar et al 2018). Recent work has also emphasised the importance of submesoscale (eddy) currents for heat transfer in the upper layers of the ocean and this is particularly significant for modulation of N. Atlantic SST in winter when winds are at their strongest (Su et al 2018).

Although it is well-established that mean global SST has increased by about $1^{\circ} \mathrm{C}$ since 1900 (Huang et al 2017), a sector of the SPG centred near $50^{\circ} \mathrm{N}, 40^{\circ} \mathrm{W}$ has experienced a pronounced relative cooling approaching $1^{\circ} \mathrm{C}$ over the same period (Drijfhout et al 2012, Rahmstorf et al. 2015; Josey et al 2018; Caesar et al 2018 and Fig 2a). This almost unique region of long term surface cooling is sometimes referred to colloquially as the 'cold 
blob' (CB) (Rahmstorf et al 2015) when mapped as the regression of local SST changes relative to global mean values. Interest in this feature has increased because of indications that the appearance of the CB might be associated with an AMOC slowdown accompanying general global warming (Drijfhout et al. 2012, Rahmstorf et al 2015; Caesar et al 2018), thus potentially reducing the rate of delivery of warm surface water to the North Atlantic with consequent cooling effects on Europe and North America. At present it is not clear whether reductions in AMOC lead increases in the CB (Rahmstorf et al 2015, Caesar et al. 2018), whether increases in the $\mathrm{CB}$ precede the AMOC decline (Drijhout et al 2012) or whether both are parallel consequences of other ocean or atmospheric factors.

Several climate modelling studies analysing the consequences of a general increase in atmospheric $\mathrm{CO}_{2}$ levels and global surface temperatures have predicted a relative cooling of a region in the SPG (Drijfhout et al. 2012 Rahmstorf et al. 2015; Caesar et al 2018) although it is not clear precisely what conditions lead to the generation of this feature. Josey et al (2018) concentrated mainly on the apparently similar 'Atlantic cold anomaly' observed between 2014-16 which they considered to be distinct from the CB described by others. They suggested various factors which could contribute to this phenomenon including localised extreme ocean heat loss, increased meltwater from SE Greenland, strong cold northwesterly winds, wind-driven upwelling of cold currents and reduced heat transport from the south. Any of these factors could plausibly also contribute to the development of the CB in periods other than 2014-16. Although several mechanisms are particularly susceptible to seasonal influence (e.g. Greenland meltwater peaks in late summer, sea ice melt is maximal in spring and cold north-westerlies are most common in winter) previous studies have largely ignored seasonal effects on the $\mathrm{CB}$ and have concentrated on annual changes. An exception to this can be seen in the work of Caesar et al (2018) who showed that long term local SST trends in the SPG relative to global trends were lowest in early spring and highest in August.

In the present work we have used SST time series between 1900 and 2018 at grid points across the SPG to determine the intensity and position of the CB at monthly intervals throughout the year-We have compared (a) absolute rates of warming or cooling at specific locations by calculating the linear regression coefficient (slope) of grid-referenced SST time series from 1900-2018 with (b) correlation maps relating local SST to global mean SST, which can identify regions where local SST change is positively or negatively correlated with global ocean warming (Drijfhout et al 2012, Rahmstorf et al. 2015; Josey et al 2018; Caesar et al 2018). These two approaches should be consistent with each other because they are using the same data but (a) provides quantitative measures of the extent of these changes at a single grid point whereas (b) identifies the geographical regions where warming or cooling is occurring relative to global mean changes besides giving semi-quantitative measures of the intensity of the $\mathrm{CB}$. This dual approach reveals a pronounced seasonal variation in $\mathrm{CB}$ intensity, with a winter maximum seen against a background of summer warming which is strongest in the western coastal region of the SPG and Baffin Bay. These localised summer warming effects incidentally cast some light on the phenomenon of Arctic temperature amplification. 
Fig 1: The area between approximately $40^{\circ} \mathrm{N}-75^{\circ} \mathrm{N}$ and $80^{\circ} \mathrm{W}-10^{\circ} \mathrm{W}$ including Greenland $(\mathrm{G})$, Labrador $(\mathrm{L})$ and Newfoundland $(N)$ showing the relation of $C B$ epicentre $\left(53^{\circ} N 36^{\circ} \mathrm{W}\right.$, blue star)to the subpolar gyre (SPG) which is bounded by the East Greenland Current (EGC), the Labrador Current (LC), the North Atlantic Current (NAC) and the Irminger Current (IC). The blue arrow corresponds to the East Greenland Coastal Current (EGCC) and B and F identify Baffin Bay and Fylla Bank respectively. N, S, E and W mark points referred to later in the text which are outside the $S P G$ and respectively about $15^{\circ}$ due north, south, east and west of $C B$ epicentre. Solid lines:warm currents; dashed lines cold currents. This figure is a modification of one in Sunby \& Drinkwater (2007) and is used with permission of the authors.

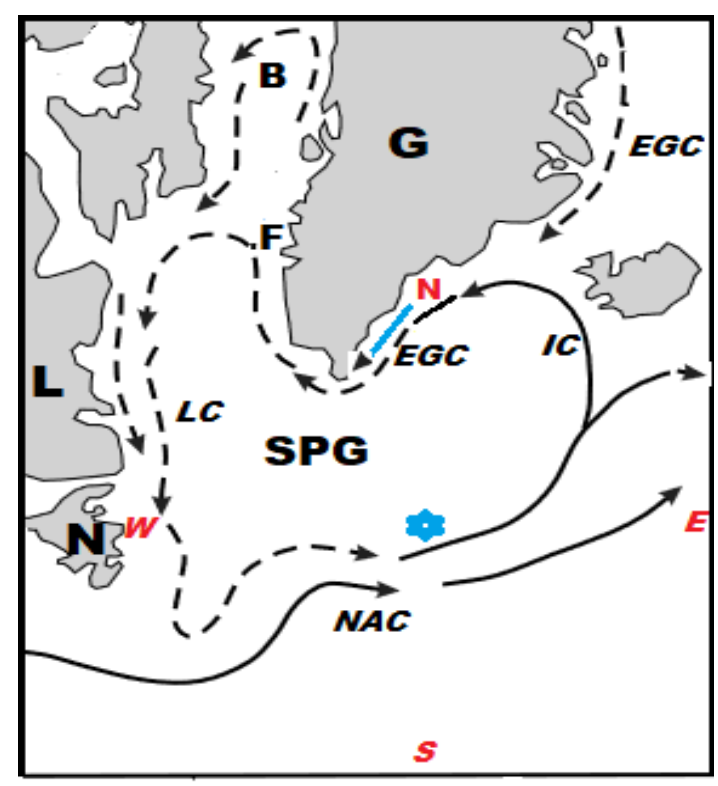

\section{Data and Methods}

Sea surface water temperature data (monthly averages) are taken from the Extended Reconstructed Sea Surface Temperature version 5 (ERSST.v5) based on Huang et al. (2017) and sea ice cover data based on the UK Met Office EN4 analysis (Good et al. 2013, Rayner et al 2003). We concentrate on the period 1900-2018 while noting that the older data is less complete, probably less accurate and depends to some extent on interpolation. Where specific geographical points are referred to in the text, they are based on ERSST data for areas covering $2^{\circ}$ of latitude and $4^{\circ}$ of longitude e.g. $50^{\circ} \mathrm{N} 35^{\circ} \mathrm{W}$ represents $49^{\circ}-51^{\circ} \mathrm{N} 33^{\circ}-37^{\circ} \mathrm{W}$. We use the term 'SST slope' to mean the gradient or trend $\left({ }^{\circ} \mathrm{C} / 100 \mathrm{yrs}\right)$ of the line of best fit through annual or monthly ERSSTv5 data points at specified grid points over the period 1900-2018.

Correlation diagrams illustrated the correlation coefficients (r) between grid-point ERSST values and global mean ERSST values. Positive correlations are labelled in shades of red and negative correlations in shades of blue according to the figure legends. We have included a test for statistical significance to identify where correlation is significant at the $95 \%$ confidence level using a two tailed student t-test accounting for autocorrelation (Yang and Tung 1998).

\section{Results}

Figure 2 shows the linear regression correlation coefficient for February (a) and August (b) ERSST grid-point values and global mean ERSST values from 1900-2018. During this period mean absolute global SST increased 
by over $1{ }^{\circ} \mathrm{C}$ (Huang et al 2017) and the positive correlations in Fig. 2a denote that the general increase in global SST is widespread but with strongest correlations in the tropics and Southern Ocean. Although positive correlations do not necessarily also imply positive trends, the robust nature of the global increase in SST relative to interannual variability and the comparison with absolute SST trends (not shown) makes this interpretation is reasonable There is one prominent region of the world which shows a strong negative correlation (interpreted as relative cooling): that is in the North Atlantic centred on approximately $55^{\circ} \mathrm{N}, 40^{\circ} \mathrm{W}$ (Fig. 2), consistent with the location of the CB identified previously (Drijfhout et al. 2012, Rahmstorf et al 2015 and Josey et al 2018). In February there was also a wide region in the N. Pacific extending from about $160^{\circ} \mathrm{E}$ to $140^{\circ} \mathrm{W}$ near $40^{\circ} \mathrm{N}$ which showed a very faint relative cooling and could be described as a hole in the overall warming of the Pacific. In addition, we noticed a smaller region of apparent cooling near the US southeast coast, which could be of interest since it is close to the origin of the Gulf Stream, but this was not examined further. In August (Fig. 2b) the most obvious difference with February is in the N Atlantic where the CB region is reduced to a 'warming hole' with no negative correlations with the global mean SST. The N. Pacific warming hole seen in February is almost absent in August and the area of negative correlation near Florida seen in February is absent in August. Also, in August there was a hint of a southern hemisphere winter cold blob close to Antarctica around $140^{\circ} \mathrm{W}$.

Fig 2. Correlation between grid point and global mean ERSSTv5 for (a) February and (b) August over the period 1900-2018. A contour denotes where correlation is significant at the $95 \%$ confidence level; the paler colours of lower correlation (generally smaller in magnitude than 0.3) correspond with the few regions where correlation is not deemed significant

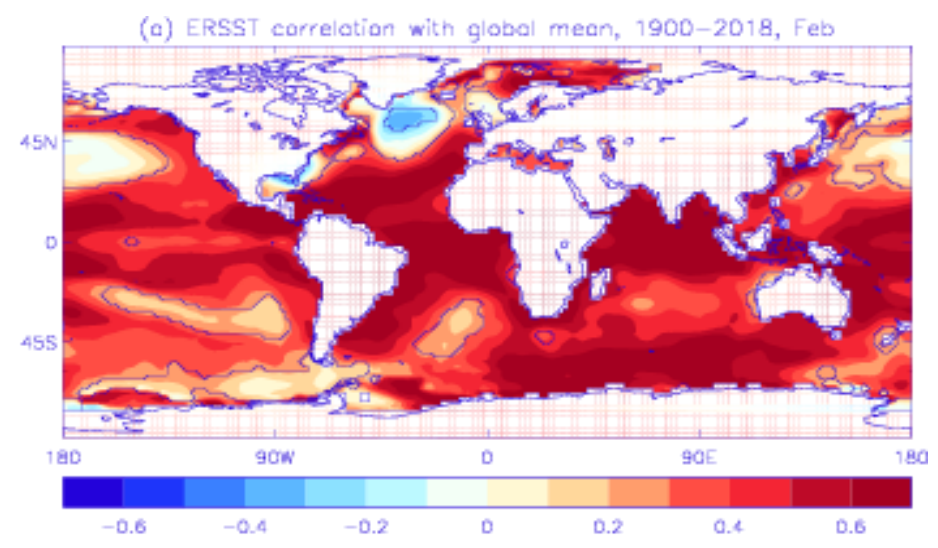

(b) ERSST correlation with global mean, 1900-2018, Aug

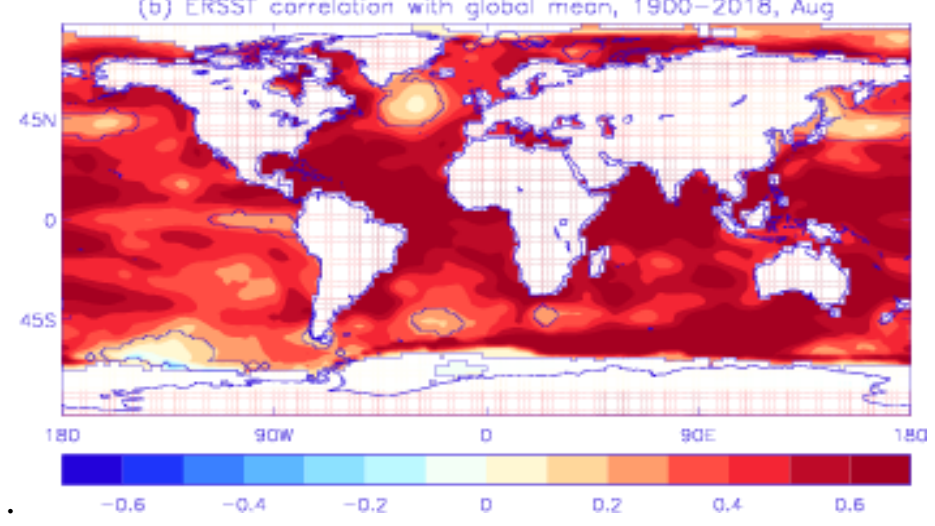

We investigated in more detail the seasonal variation in intensity and position of the CB based on monthly ERSST v5 data from 1900 to 2018 (Fig. 3). It is most prominent early in the year (particularly January and February) in the SPG near $53 \mathrm{~N}^{\circ} 36^{\circ} \mathrm{W}$ but during March and April the CB fades and by May the coastal region 
of SE Greenland near $65^{\circ} \mathrm{N}$ becomes the region of strongest negative correlation, which we take as an indication of relative cooling. Between May and August there is a continued reduction in the 'warming hole' (Josey et al. 2018) but the CB, as a negative anomaly, largely disappears. Beginning in September there is enhanced relative cooling in coastal SE Greenland at about $65^{\circ} \mathrm{N}$ and through October, November and December this cooling extends into the SPG and up the SW Greenland coast. By January and February, the coolest region is centred on $53^{\circ} \mathrm{N}, 36^{\circ} \mathrm{W}$ to form the classic $\mathrm{CB}$ as seen in Fig. 2. Areas of strong positive correlation (red), indicative of relative long term warming off the coast of Newfoundland/Labrador and extending up the Davis Strait into Baffin Bay also show marked seasonal variation, with more intense red hues seen in the summer months fading in the winter as the $\mathrm{CB}$ develops.

The monthly pattern of surface changes revealed in Fig 3 is most easily interpreted in terms of the development of a region of cold surface water in autumn close to the SE Greenland coast which in the next few months appears to migrate across the SPG to form the CB in January/February. Although this interpretation might be attractive, our present evidence for it is indicative and only circumstantial. There are obvious complications in the interpretation of these correlation diagrams because the expression of the cold surface events which generate the $\mathrm{CB}$ and the cold region adjacent to the SE Greenland coast are likely to be contaminated by long term warming effects which are most evident in summer along the coasts of Labrador and W. Greenland (Fig. 3). Without these warming effects the coastal cool strip along the SE Greenland coast in autumn might be more evident and the CB might persist through the summer instead of being only a 'warming hole'. However, warming effects are much less in the winter particularly near coasts subject to sea ice (Fig 3) so that observations of the CB in January and February are likely to be more reliable indicators of the true cold anomaly. 
Fig 3. The seasonal manifestation of the North Atlantic 'cold blob'. Monthly ERSST grid point data (Huang et al 2017) for years from 1900 to 2018 were regressed on the mean global values. The bar beneath registers correlation coefficients (negative correlation in shades of blue, positive correlations in shades of red). Stippling is used to denote where correlation is significant at the $95 \%$ confidence level.
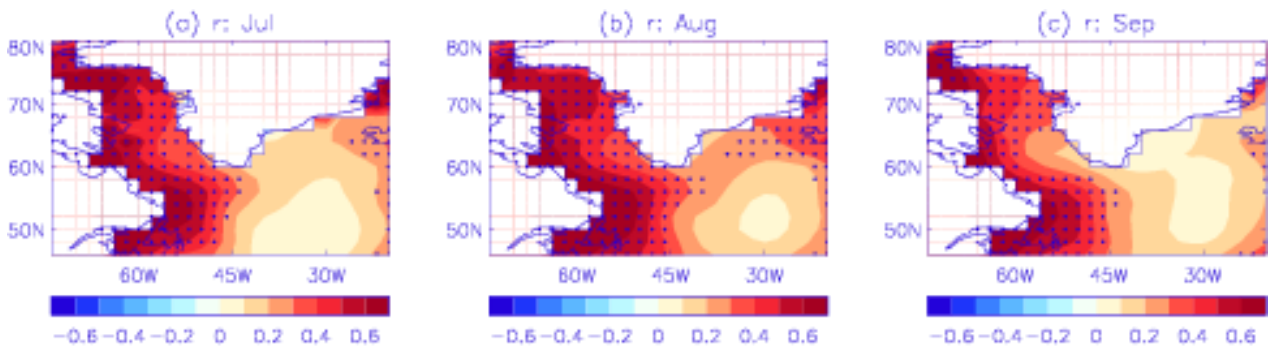

(d) $r:$ Oet
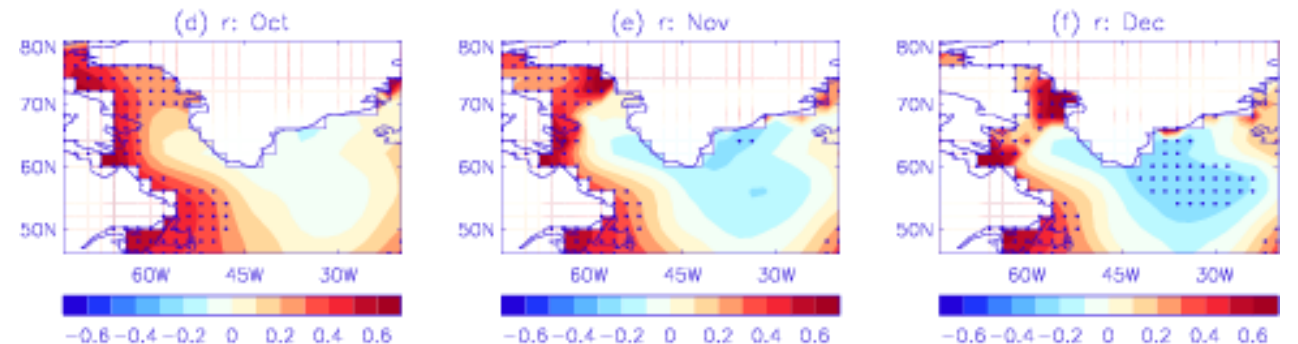

(g) r: Jon
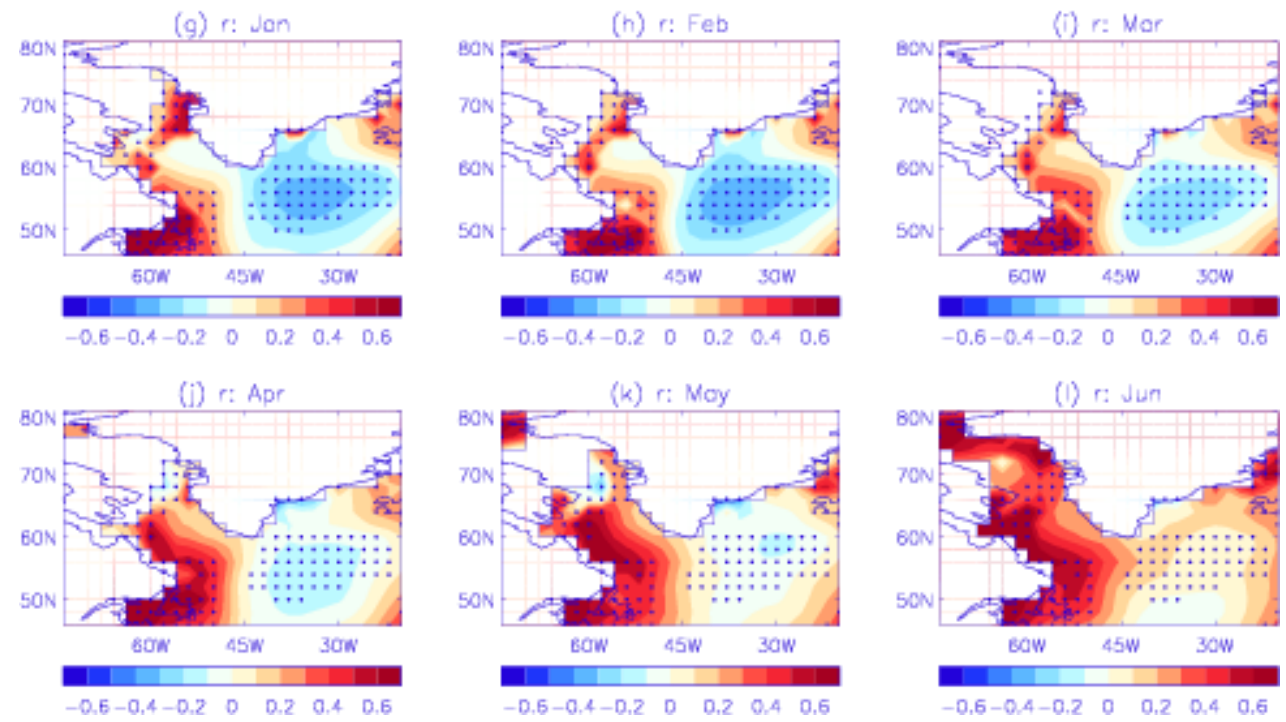

The localisation of the CB to an area of the SPG centred on $53^{\circ} \mathrm{N}, 36^{\circ} \mathrm{W}$ (CB epicentre) was confirmed by quantitative measurements of SST slope derived from the time series of February ERSST measurements from 1900-2018 within a grid covering the area between $45^{\circ}-65^{\circ} \mathrm{N}$ and $60^{\circ}-10^{\circ} \mathrm{W}$ (Fig. 4). The area of negative slope in Fig. 4 extends from approximately $40^{\circ}-65^{\circ} \mathrm{N}, 45^{\circ}-20^{\circ} \mathrm{W}$ and this corresponds well with the February CB in Figures 2-3 and with previous reports (Drijfhout et al. 2012 and Rahmstorf et al 2015). The area of most negative SST slope is centred around $53^{\circ} \mathrm{N}, 36^{\circ} \mathrm{W}$ but there is a significant subsidiary trough near $64^{\circ} \mathrm{N} 38^{\circ} \mathrm{W}$ close to the SE Greenland coast which corresponds with the area of the Greenland coast experiencing relative cooling at certain times of year (Fig. 3). The most negative SST slope values at $53^{\circ} \mathrm{N}, 36^{\circ} \mathrm{W}$ in Fig 4 represent cooling of almost $0.9^{\circ} \mathrm{C} /$ century in February and confirm that in winter the epicentre of the $\mathrm{CB}$ (the region of greatest negative SST slope) is an area of absolute long term cooling and not merely a 'relative warming minimum' (Suo et al 2017), 'warming hole' (Drijfhout et al. 2012) or short term 'cold anomaly' (Josey et al. 2018). It is notable that at the western and northern extremes of the range of both latitude and longitude, SST slope is positive, corresponding to warming rather than cooling and this accords with the strong red tones in Fig. 3 indicative of warming seen in summer in the coastal areas around Newfoundland and extending up towards Baffin Bay. 
In contrast to the February SST slope in Fig 4, which accurately delineates the CB, the August SST slope is only weakly associated with the CB region and remains positive across the whole of the SPG, particularly near the Labrador coastal region $\left(>50^{\circ} \mathrm{W}\right)$ which shows very high latitudinal values approaching $+2^{\circ} \mathrm{C} /$ century . Again. this is consistent with the long term warming seen near Newfoundland and Labrador in summer (Fig. 3ab). Calculating the slope of August SST minus the slope of February SST values (black,) shows how the annual range of SST slope has changed over time i.e. the difference between summer and winter rates of warming since 1900. This displays a positive and significant latitudinal value greater than $0.8^{\circ} \mathrm{C} /$ century between $40^{\circ} \mathrm{N}$ and $64^{\circ} \mathrm{N}$ (Fig. 4a). Longitudinal slope in the annual range of SST (Fig 4b) is highest close to the Newfoundland coast (about $2^{\circ} \mathrm{C} /$ century) but much lower $\left(0.3{ }^{\circ} \mathrm{C} /\right.$ century) E of the SPG at $54^{\circ} \mathrm{N} 15^{\circ} \mathrm{W}$ (Fig 1 ).

Fig 4 SST slope and range of SST slope across the N. Atlantic.

Latitudinal section at $36^{\circ} \mathrm{W}\left(35^{\circ}-37^{\circ} \mathrm{W}\right)($ a $)$ and longitudinal section at $54^{\circ} \mathrm{N}\left(53^{\circ}-55^{\circ} \mathrm{N}\right)$ (b) showing SST slope $\left({ }^{\circ} \mathrm{C} / \mathrm{y}\right.$ x100) for February (blue), August (red) and (August minus February) (i.e. SST annual range slope, black) 1900-2018 at selected points across the SPG. Filled circles denote where correlation is significant at the 95\% confidence level.
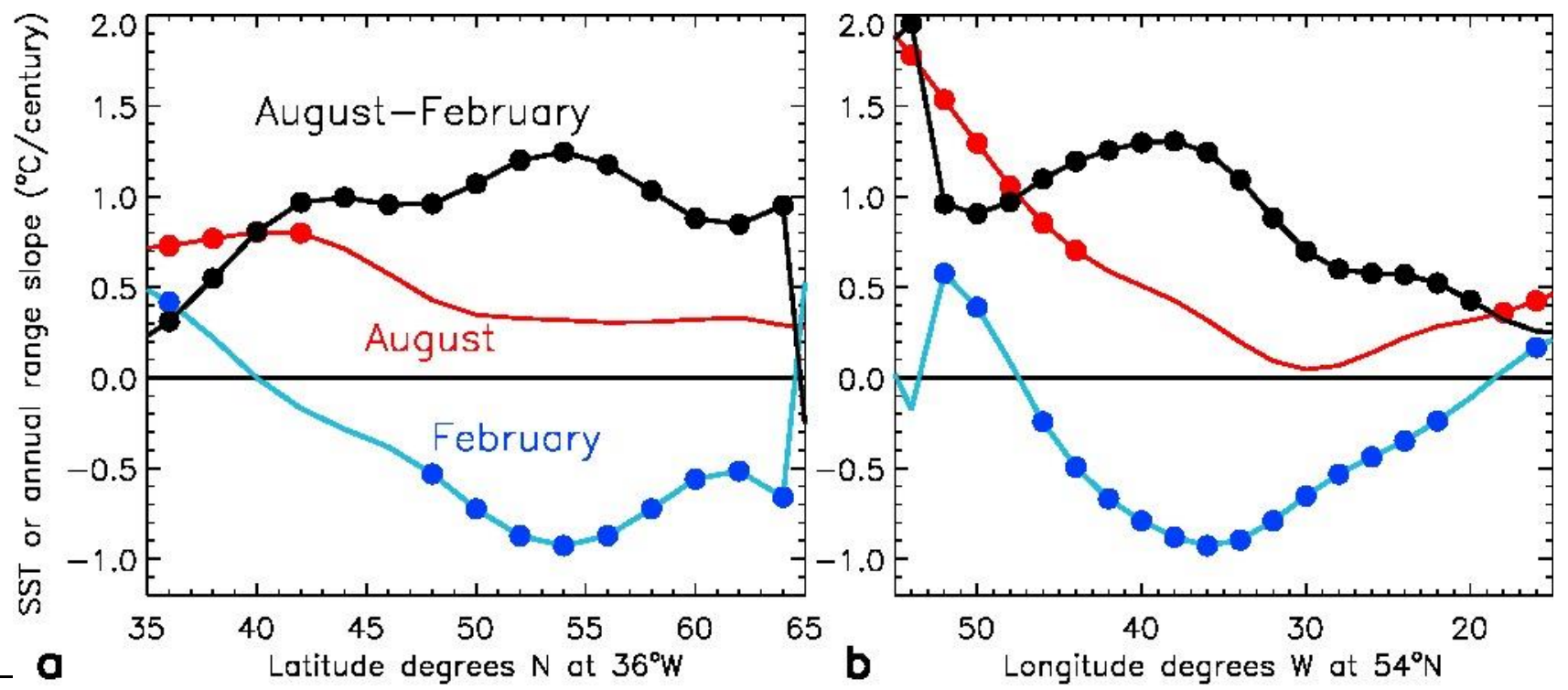

The monthly variation of SST slope at the CB epicentre $\left(54^{\circ} \mathrm{N}, 36^{\circ} \mathrm{W}\right.$ ) (Fig. 5a) parallels the seasonal variation of the $\mathrm{CB}$ with a minimum in February corresponding to the greatest intensity of the $\mathrm{CB}$ and a maximum in August corresponding to the small warming hole seen in Fig 3. It is notable again that even at CB epicentre there was net long-term warming from July to September. The SE Greenland coast at $64^{\circ} \mathrm{N}, 36^{\circ} \mathrm{W}(\mathrm{N}$ of $\mathrm{CB}$, Fig. 5a) shows an even more negative SST slope than the CB epicentre from September to December but a more positive SST slope for the period from January to April, consistent with the appearance of relatively cooler surface water in the SE Greenland coastal area in autumn and the apparent transfer of this cooling signal southwards towards the $\mathrm{CB}$ epicentre in winter as inferred from Fig. 3. The overall shape of these two curves are quite similar and clearly related to the curves for Baffin Bay, Fylla Bank and W of CB suggesting that CB epicentre and $\mathrm{N}$ of $\mathrm{CB}$ share part of the strong summer warming influence of the colder northern and western regions. Fylla Bank on the SW Greenland coast shows stronger summer warming than CB epicentre and the SE Greenland coast ( $\mathrm{N}$ of $\mathrm{CB}$ ) but shares with these regions the strong cooling in winter, consistent with the known flow of coastal currents from SE Greenland around Cape Farewell into SW Greenland (Fig 1) and with Fig 3.

These seasonal trends are confirmed and widened in Fig. 5b which compares the long term slope in the annual SST range (August minus February) in various parts of the world. In contrast to the northern hemisphere, the 
average August minus February SST range slope is negative over the southern hemisphere but this means that both hemispheres are experiencing a long term increase in the annual range in SST (summer minus winter). For the whole world and the southern hemisphere, changes in seasonal differences are quite small (less than $0.1^{\circ} \mathrm{C} /$ century in magnitude) but the northern hemisphere shows a bigger difference (about $0.4^{\circ} \mathrm{C} /$ century). Contributing to this are the very large seasonal changes observed in western coastal regions of the SPG (W of $\mathrm{CB}$ and Fylla Bank) and particularly in Baffin Bay where the slope in the annual range of SST approaches $2^{\circ} \mathrm{C} /$ century. However, the range slope is much lower to the east $\left(0.3^{\circ} \mathrm{C} /\right.$ century $)$ and south $\left(0.2^{\circ} \mathrm{C} /\right.$ century $)$ of the $\mathrm{CB}$ and quite similar to worldwide values. The $\mathrm{CB}$ epicentre and the most northerly point in Fig. 4 near the SE Greenland coast ( $\mathrm{N}$ of $\mathrm{CB}$ and $\mathrm{N}$ in Fig. 1) also have a comparatively high seasonal range but this is likely to be inflated by the particularly low February values characteristic of these two regions.

Fig 5. Seasonal changes in SST slope. (a) Mean SST slope for each calendar month in the years from 1900-2018 was calculated for CB epicentre (blue), West of CB (purple), E of CB (orange); N of CB (red), Baffin Bay (black) and Fylla Bank (green). Filled circles denote significant correlation at the 95\% confidence level. (b) The net annual SST range slope (equivalent to August SST minus February SST slope values) for various regions of the world (filled circles denote where magnitude of average $r$ is greater than 0.3 to approximate where statistically significant). $N$ of $C B\left(64^{\circ} \mathrm{N} 36^{\circ} W\right), E$ of $C B$ $\left(54^{\circ} \mathrm{N} 14^{\circ} \mathrm{W}\right), \mathrm{S}$ of $C B\left(36^{\circ} \mathrm{N} 36^{\circ} \mathrm{W}\right)$ and $\mathrm{W}$ of $\mathrm{CB}$ near the Labrador coast at $52^{\circ} \mathrm{N} 54^{\circ} \mathrm{W}$ represent respectively the northernmost, easternmost, southernmost and westernmost points in Fig 4 and are identified as $N, E, W$ and $S$ in Fig 1. Baffin Bay represents the area between $67^{\circ} \mathrm{N}-75^{\circ} \mathrm{N}$ and $75^{\circ}-55^{\circ} \mathrm{W}$ and Fylla Bank is in coastal W Greenland between 64 and $54^{\circ} \mathrm{W}$. CB epicentre is at $54^{\circ} \mathrm{N} 36^{\circ} \mathrm{W}$. NH and SH stand for the entire Northern and Southern Hemispheres respectively.
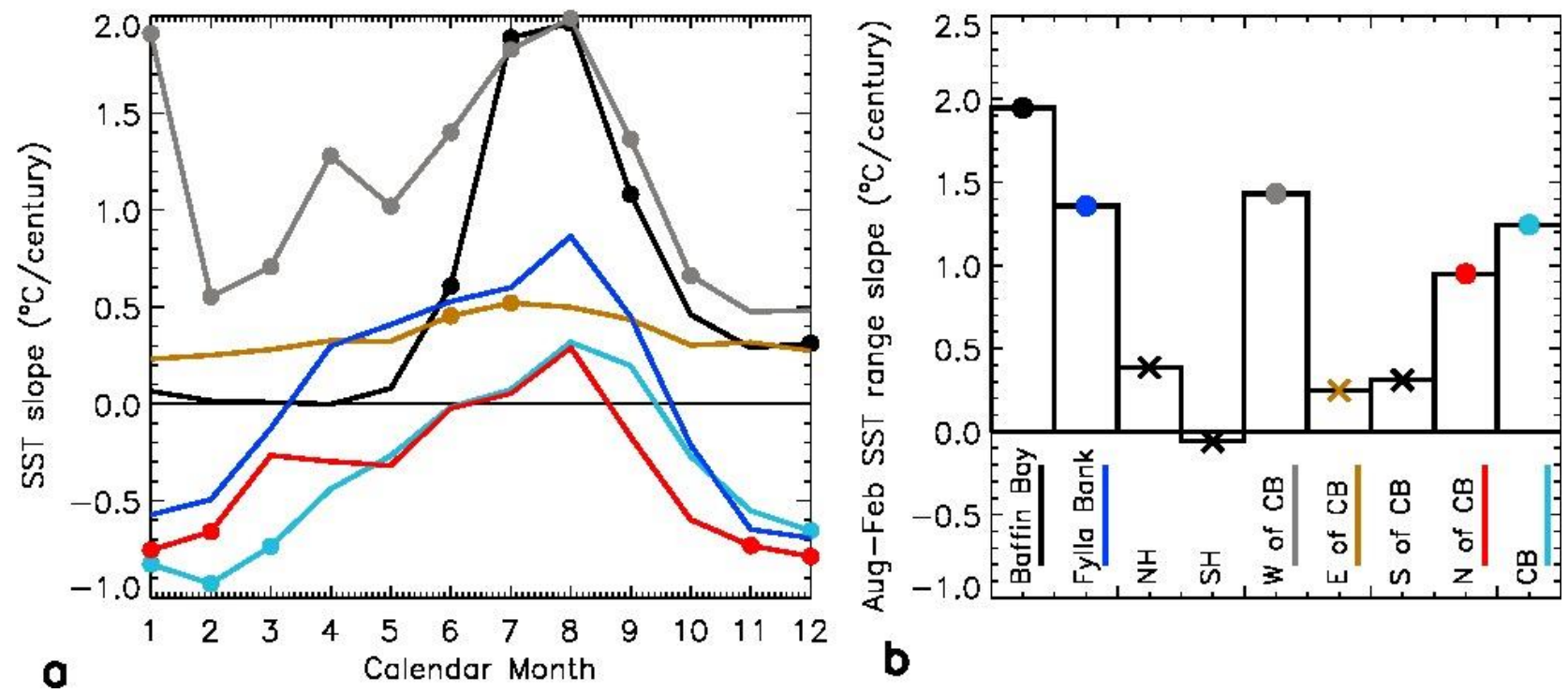
Fig 6. Global map of ERSST annual range slope (trend).

This diagram is based on grid point values for (August SST minus February SST) slope. The scale is ${ }^{\circ} \mathrm{C} / \mathrm{century}$ using 1900-2018 data. Stippled regions denote where correlation is significant at the 95\% confidence level.

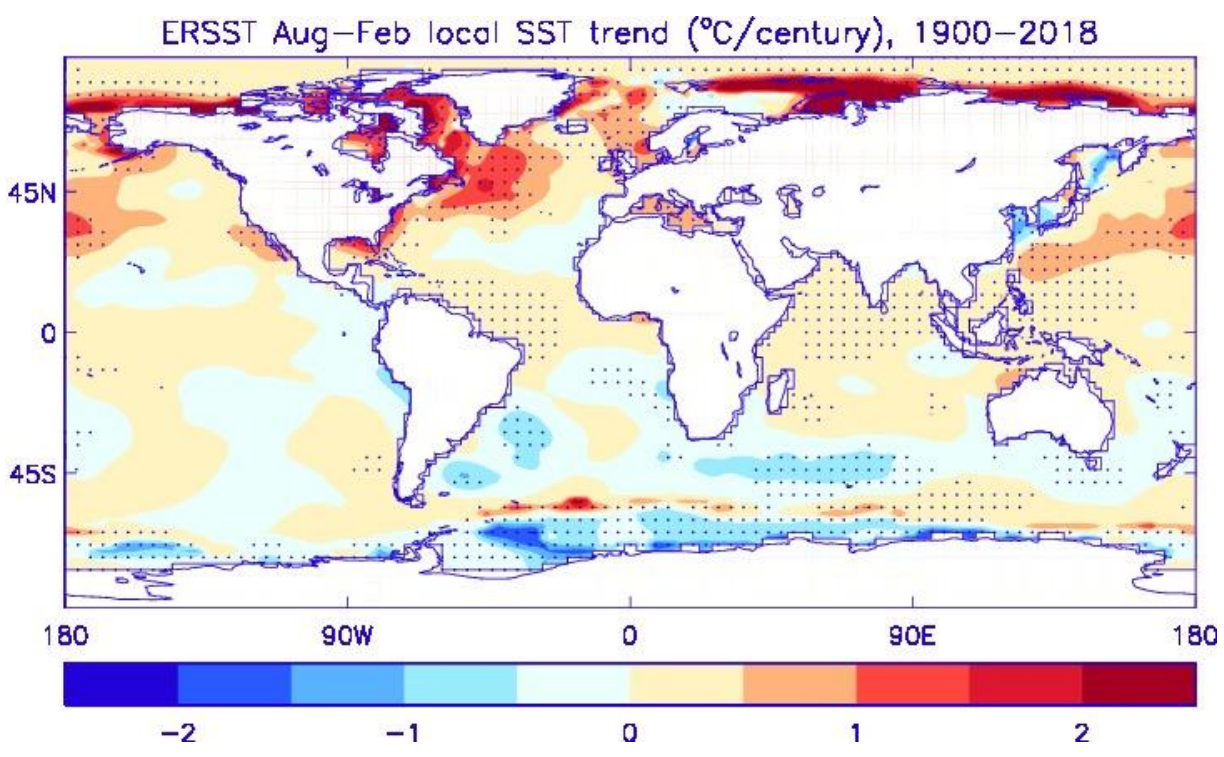

The results shown in Fig 5b are extended by global comparisons of long term changes in SST annual range (Fig. 6) which confirm the large positive SST annual range slopes in Baffin Bay and coastal Labrador but also show very high values ( $>2 \%$ century) along the Arctic coasts of Russia and North America. Similar but less marked increases in SST annual range (summer minus winter) are also seen close to the Antarctic coast as evidenced by the strong blue colours.

Fig. 7 clarifies the reasons for the marked summer long term warming in the western part of the SPG near the Labrador coast and for other areas to the north including Baffin Bay. For August 1910-1920 Baffin Bay was colder by about $1.5^{\circ} \mathrm{C}$ than the long term average but in the first 20 years of the $21^{\text {st }}$ century it was about $1.5^{\circ} \mathrm{C}$ warmer (Fig. 6a). This explains the large positive value of August SST slope for Baffin Bay $\left(+2^{\circ} \mathrm{C} / \mathrm{century}\right.$ based on 1900-2018, Fig. 5a) and for the large seasonal range in SST slope (Fig. 5b). A very similar effect (summer cooling around 1910 and warming after 2000) is seen further south along the Newfoundland coast (not shown), at Fylla Bank in SW Greenland, and at W of CB (Fig. 7a). These areas are normally subject to severe winter sea icing but it is clear from Fig. 6b that in the years around 1918 heavy sea ice persisted until August in Baffin Bay, much later than any period before or since. This unusual cold event contributed to anomalously low SST values in summer (Fig 7b) and thus a low baseline for the evaluation of SST slope since 1900, with a consequently increased SST slope over the period 1900-2018. That might be considered to be an artefact but it nevertheless would be recorded as a sub-Arctic summer warming effect in terms of SST slope or in correlation diagrams (e.g. Fig. 3). It is important to note that SST measurements are limited by the freezing point of sea water so that ice-covered regions are arbitrarily assigned an SST of $-1.8^{\circ} \mathrm{C}$ in datasets (Rayner et al 2003; Good et al. 2013) even when the temperature of the ice is much lower. This means that using the nominal values of SST around 1910-20 gives an overestimate of the 'true' baseline and hence an underestimate of apparent warming since that period. 
The marked August warming since about 1990 is particularly evident in Baffin Bay and coastal regions; including Fylla Bank and W of CB. In contrast, $\mathrm{E}$ of $\mathrm{CB}$ (the region at the extreme east of the area covered by Fig. 4a which has never been affected by sea ice and is outside the SPG) showed no evidence for the 1918 cold period and correspondingly little evidence for unusual summer warming or increase in SST slope (Fig.5)

\section{Fig 7. Long term SST changes in the sub-Arctic and their relation to summer sea ice concentration.}

a. Time series (5 year moving averages) for August ERSST 1880-2018 for the regions $W$ of CB (purple), $E$ of CB (red), CB epicentre (blue), Fylla Bank (green) and Baffin Bay(black). (see legend to Fig 1 and Fig $5 B)$.

b. August sea ice concentration in Baffin Bay 1900-2018. Note the observational hiatus from 1940 to1952.
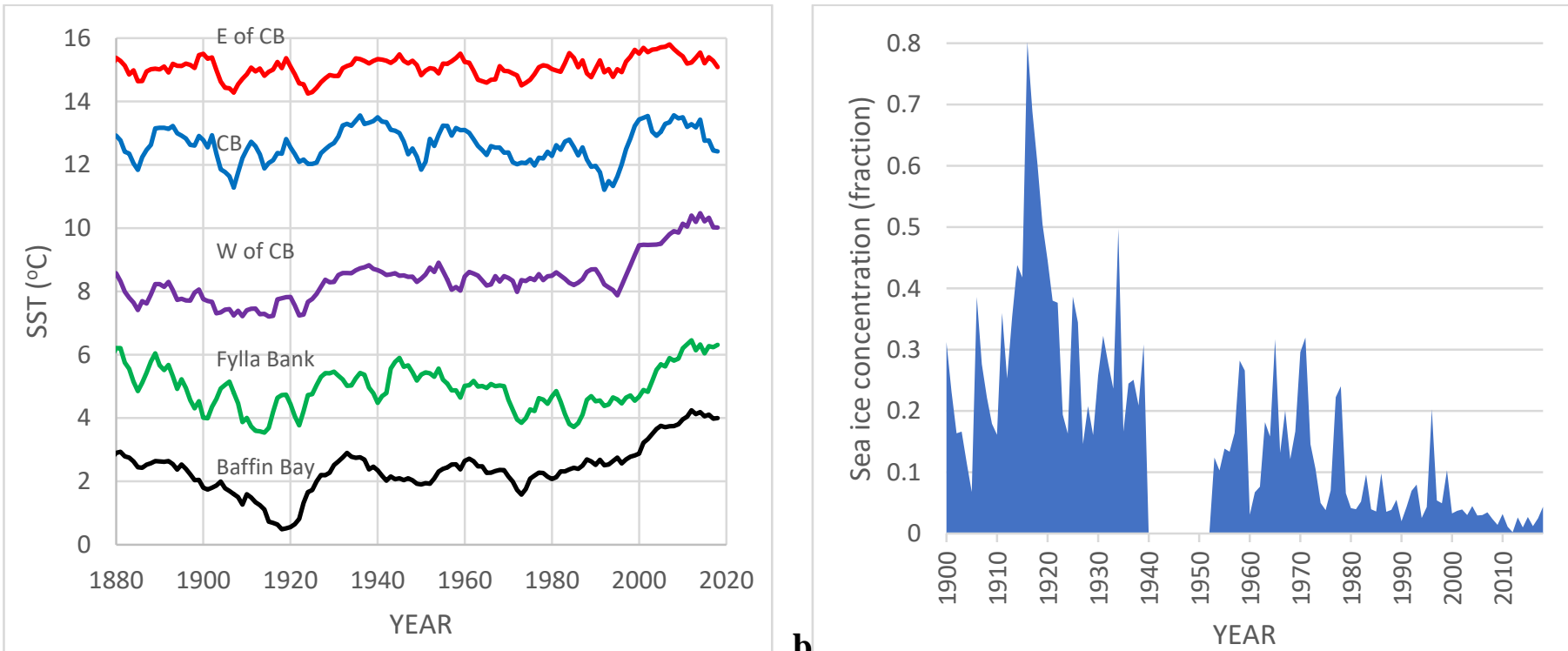

It is clear from Fig 7b that since about 1980 there has been very little August sea ice in Baffin Bay compared with the high levels observed previously and this suggests an explanation for the enhanced warming after 1990: this recent large drop in summer sea ice has created more open water exposed to insolation, consequently warming these sub-Arctic seas disproportionately in summer. Reduced summer sea ice in recent years means more open water than in the past so that summer insolation is more effective in warming the sea surface than it used to be in areas like Baffin Bay. E of CB and S of CB in contrast (like most of the lower latitude ocean surface) show very little enhanced summer warming (Fig 7a,b) because these regions have never been covered by sea ice in recent times and thus there would be no new open water to be warmed by the summer sun. This effect is likely to be general in sub-Arctic regions which have lost summer sea ice in recent years but will now also be a growing factor in the high Arctic which is losing ice in July and August which was never lost in the past (e.g. the Arctic coasts of Russia and N. America, Fig 6.).

This long term summer warming effect due to the recent disappearance of summer sea ice is shared by all the sites within the SPG including the CB because they all show a similar seasonal cycle of annual SST slope (Fig. 5a) but with the effect diminishing towards the east and south (Fig 4,5a). The effect is very consistent with the long term relative warming (dark red hues) observed near Newfoundland and Labrador in Fig. 3, particularly in summer. Without such an effect it can be surmised that the CB would be even more obvious than it is because 
the long term cooling in the $\mathrm{CB}$ region would not be obscured by the extraneous summer warming influence which is strongest in Baffin Bay but whose influence extends into the SPG.

A short term increase in SST slope in recent decades has affected the whole world, with annual mean global SST slope since 1990 accelerating to about $0.13^{\circ} \mathrm{C}$ per decade compared with the century from $1900-2000$ when it was about $0.07^{\circ}$ per decade (Huang et al 2017). However, in regions which have always experienced severe winter sea icing (e.g. Baffin Bay and W of CB, Fig. 6a) the 1990-2018 mean annual SST slope has been much greater e.g. in coastal Labrador it has been about $2^{\circ} \mathrm{C}$ since $1990\left(0.7^{\circ} \mathrm{C}\right.$ per decade $)$ or more than twice the rate seen in the whole Northern Hemisphere. This is consistent with other evidence which shows an amplification of global warming in the Arctic related to diminishing sea ice (Screen and Simmonds, 2010; Simmonds 2015). It should be noted additionally that this Arctic amplification effect might also be observed as a result of the artefactual long term warming effect noted above as a result of the unusually high level of summer sea ice and cold temperatures in Baffin Bay around 1915.

\section{Discussion}

\section{The Origin of the $C B$}

The 'cold blob'(CB) represents an almost unique area of long term sea surface cooling centred on approximately $53^{\circ} \mathrm{N}, 36^{\circ} \mathrm{W}$ that has been associated with weakening of the Atlantic Meridional Overturning Circulation (AMOC) and consequent reduced transport of heat northwards by ocean currents (Drijfhout et al 2012; Rahmstorf et al 2015; Caesar et al.2018). While links between atmospheric circulation, AMOC strength and variability in the north Atlantic SST have been presented in modelling (e.g. Latif et al. 2019) and observational studies (e.g. Desbruyeres et al 2019; Josey et al. 2018), the precise processes are complex and poorly understood (Robson et al. 2019). Here we have investigated in more detail the characteristics of the CB and attempt to rationalise seasonal changes in its intensity and spatial structure.

We have shown here that the epicentre of the $\mathrm{CB}$ is a region of absolute (not merely relative) long term winter cooling (Fig 4) but that in addition there is a strong seasonal influence on the shape and intensity of the CB (Fig 3). In winter, absolute cooling of about $0.9^{\circ} \mathrm{C}$ since 1900 is observed at the $\mathrm{CB}$ epicentre (Fig. 4-5) but even here there is net warming in summer. Caesar et al. (2018) also noted a seasonal change in SST trend in the SPG with a negative SST trend in spring and a positive trend in summer and Suo et al (2017) implied a similar effect from modelling studies. Our findings do emphasise that the CB represents a more compact area in winter than is evident from work which did not use the full annual monthly cycle as we do here. For example, Caesar et al. (2018) used the November to May period and Duchez et al (2016) removed the seasonal cycle from their data. Thus previous work has failed to identify the pronounced seasonal changes in the shape and intensity of the CB and consequently has missed not only the relatively discrete character of the CB in winter but also the details of what appear to be surface connections between the $\mathrm{CB}$ and coastal Greenland (Fig. 3). Attention to the monthly detail of changes in the $\mathrm{CB}$ has also allowed us to show that at $\mathrm{CB}$ epicentre in winter, there is an absolute (not merely relative) long term cooling which approaches $1^{\circ} \mathrm{C}$, something which has not been clear from previous work.

The enhanced cooling seen in autumn close to the SE Greenland coast in Fig. 3 could be of particular significance because this region between Denmark Strait and Cape Farewell corresponds to the East Greenland Coastal Current (EGCC), a narrow band of colder water which has been proposed to be maintained by efflux of icebergs and meltwater from the Greenland ice cap (Bacon et al 2002) together with melting seasonal sea ice (Sutherland and Pickart, 2008, Harden et al. 2014, Lin et al. 2018). It is known that the EGCC mixes with the 
EGC when joining the SPG at Cape Farewell (Bacon et al 2002; Sutherland and Pickart 2008, Lin et al. 2018) and thus can enter the arc of currents which could potentially take cold surface water into the West Greenland Current and thence around the western SPG into the region of the southern SPG where it could eventually reach CB epicentre (Fig. 1).

However, there is observational evidence for transport of a portion of the combined EGC/EGCC more directly towards the centre of the SPG and potentially to the CB region. Holliday et al (2007) identified a new pathway for fresh water into the interior of the subpolar gyre whereby about a third of the EGC/EGCC rounding Cape Farewell was retroflected southwards across the SPG. This was observed in August/September as a cold, fresh subsurface current but could potentially provide the source of the cooler surface water seen later in the winter in the CB (Fig. 3). A comparable fresh water deficit in the coastal current at Cape Farewell was observed by Lin et al. (2018) who provided evidence for offshore movement of this fresh water towards the centre of the SPG. Such a pathway could be activated by the Greenland tip jet (Pickart et al. 2003; Våge et al. 2009) generating north westerlies, reputed to be the strongest winds in the world, around Cape Farewell which in winter appears to be sporadically capable of sweeping surface water from the Greenland coast deep into the SPG. Thus, there are two possible routes by which cold surface water originally derived from melting SE Greenland icebergs or sea ice might reach CB epicentre and one of these routes may be manifested in Fig. 3 as a tongue of cold water originating in SE Greenland in autumn and apparently building the CB in winter.

From measurements of surface current velocity in the SPG (about $0.2 \mathrm{~m} / \mathrm{sec}$, Frantantoni 2001 and Flatau et al. 2003), an estimate can be made of the time it would take for surface water to traverse directly the $900 \mathrm{~km}$ between Cape Farewell and CB epicentre. This gives a result of about 2 months, which can explain a large proportion of the lag time between cold water being observed in coastal Greenland in November and intensification of the CB in January/February (Fig. 3). By comparison it would take more than a year for surface water to move the $6000 \mathrm{~km}$ distance between Cape Farewell and CB epicentre if it was carried in the boundary currents around the SPG.

Our tentative suggestion that the CB could have its origin in iceberg and sea ice melt in coastal Greenland is different from the speculations of Rahmsdorf et al. (2015) that meltwater and iceberg discharge from the Greenland ice sheet may have contributed to an observed freshening trend which could have weakened deep water formation, thus slowing AMOC. This hypothesis sees the CB as a secondary consequence of a decrease in AMOC (Caesar et al 2018) as do other schemes (e.g. Latif et al. 2019) which stress the primacy of atmospheric rather than oceanic changes. On the other hand, our evidence (Fig. 3) is more consistent with a direct seasonal transfer of cold waters from coastal Greenland to CB epicentre across the SPG. This could proceed via the mechanism suggested by Holliday et al (2007) and partly supported by Lin et al. (2018) whereby the combined EGCC/EGC was split at Cape Farewell and a substantial but variable quantity of cool fresh water would be ejected towards the centre of the SPG where it could supply the CB. An increased quantity of water diverted into this route implies a decrease in the strength of the currents around the SPG and possibly a decrease in AMOC. This view would see decrease of AMOC and strengthening of the $\mathrm{CB}$ as parallel consequences of diversion southwards of part of the combined EGCC/EGC at Cape Farewell.

\section{Sub-Arctic Temperature Amplification in Regions Subject to Seasonal Sea Ice}

The precise seasonal distribution of cool surface water which contributes to the development of the CB is difficult to establish because the SPG is subject to extraneous and variable summer surface warming. However, part of the seasonal difference in long term SST anomaly in the CB appears to be due to a particular phenomenon affecting the Atlantic north of $40^{\circ} \mathrm{N}$ and west of $15^{\circ} \mathrm{W}$ (including the SPG) which involves an 
enhanced warming effect in summer but little change in winter (Fig. 5b). This seasonal differential appears to be strongest in Baffin Bay and near the coasts of the Labrador Sea (Fig. 5), areas which are subject to extensive and persistent winter sea ice but part of this effect could be communicated by cold currents and strong NW winds to regions further south which do not normally experience sea ice.

There are several reasons why coastal regions near Greenland and Labrador such as Baffin Bay, Fylla Bank and $\mathrm{W}$ of $\mathrm{CB}$ would be more prone to sea ice than a mid-ocean site like $\mathrm{E}$ of $\mathrm{CB}$ : clearly more northerly regions would have colder temperatures and coastal regions would generally be more sheltered, allowing ocean surface stratification which is conducive to sea ice formation ( $\mathrm{Su}, 2017)$. Additionally, ocean surface regions close to the Greenland shelf are likely to have much lower salinities than the open sea due to efflux of ice and water from the ice-cap in summer and marine glaciers in autumn and this would make sea ice formation more likely as temperatures drop below zero. Finally, coastal regions in the sub-Arctic can be supplied with fresh Arctic sea ice directly through Fram Strait and the Canadian Arctic Archipelago (Belkin et al. (1998).

The most prominent regions of the recent (post 1990) summer warming effect (e.g. Baffin Bay) show enhanced summer warming in the period from about 1990 to the present day which is much greater than general global warming (Fig. 7a) and likely to be related to the fact that these peripheral areas of the Arctic have undergone the greatest changes in summer ice cover since about 1990. Enhanced warming in these regions in summer is an inevitable consequence of increases in ocean insolation due to summer ice loss and is consistent with 'the central role of diminishing sea ice in recent Arctic temperature amplification' (Screen \& Simmonds 2010). Fig 6 confirms that those areas showing the highest summer warming effects are those which have lost the most summer sea ice in recent years This is particularly true along Arctic coasts of Russia and N. America (Fig 6).

Recent work has also highlighted the importance of infrared/longwave radiation in contributing to Arctic amplification. Since the infrared spectrum in the Arctic is less saturated than warmer regions, small increases in moisture and cloud cover (or cloud base temperature) will readily increase the downward infrared radiative flux. Moistening of the Arctic lower troposphere with warming is a consequence of the Clausius Clapeyron equation that explains a greater flux of moisture from the mid-latitudes (e.g. Siler et al. 2018); consequent increases in downward longwave emission contribute further to sea ice melt. The frequency of these intrusions of moist air is further modulated by the response of atmospheric circulation patterns to climate change and diminishing Arctic ice coverage (Luo et al. 2017). Nevertheless, local processes have been shown to dominate Arctic amplification (Stuecker et al. 2018).

In addition to this amplification of polar warming driven by recent sea ice melt, increases in downward IR flux and increased poleward moisture transport by the atmosphere there is a long term effect which also increases measures of SST slope in the sub-Arctic and consequently diminishes the intensity of the CB. This depends on the observation that there was a particularly cold period in the sub-Arctic with unusually persistent and extensive summer sea ice around 1918 (Fig 7a,b) near to the time baseline often used for measurement of SST slope and hence CB intensity. Measurements of SST slope from 1900 would be increased because the baseline SST was particularly low at the beginning of the $20^{\text {th }}$ century and especially in summer this apparent long term warming effect would tend to override the long term cooling which is characteristic of the CB. This artefactual enhancement of warming might still add to apparent Arctic amplification if measurements were simply based on long term SST data. Clearly it is important to consider carefully the choice of baseline, as well as the fidelity of the early record that is based on sparse data coverage, in studies using regression correlations.

Another factor to take into account is the recent evidence that ERSSTv5 data tends to underestimate SST by up to $0.2^{\circ} \mathrm{C}$ in the period $1900-1920$ (Chan et al 2019). Correcting for this presumed error decreases SST slope at CB epicentre in February from $-0.9^{\circ}$ to $-1^{\circ} \mathrm{C} / 100 y$ (values based on ERSSTv5 data) and decreases SST slope in 
August from $+0.3^{\circ}$ to $+0.2^{\circ}$. Although this means that the CB in February and the 'warming hole' in August would be intensified we have ascertained that the baseline correction does not materially affect the results presented in this work.

Both factors (recent sea ice melt and the baseline effect of the cold period near 1918) increase SST slope in the sub-Arctic so that the largest rates of warming worldwide are seen in the coldest ocean regions with the largest amounts of seasonal sea ice e.g. Baffin Bay. The coastal summer warming effects are likely to increase the value of SST slope throughout the SPG and hence would diminish the intensity of the CB revealed in maps of relative SST anomaly (e.g. Figs. 2-3). Thus, the CB is most clearly visible in the winter not just because it is replenished by cold waters from Greenland but also because it is largely unattenuated by the summer warming effects (Fig. 3); in summer however, it is only seen as a small 'warming hole'.

We conclude that there are two seasonal effects on CB SST slope and hence on the position and intensity of the CB: (1) long term and short term summer warming effects seen most clearly in Baffin Bay but distributed widely around the SPG and especially in the Labrador coastal region, which increase SST slope (1900-2018) at the CB epicentre by about $1^{\circ} \mathrm{C} /$ century in summer and (2) a winter cooling possibly with its origin in iceberg and water discharge from the Greenland icecap and/or melting sea ice which reduces net SST slope at the $\mathrm{CB}$ epicentre by about $1^{\circ} \mathrm{C} /$ century in February (Fig. 5a). It is this cooling influence that defines the $\mathrm{CB}$, which is hardly visible when unadjusted February SST slope is more positive than $-0.3^{\circ} \mathrm{C} /$ century. Explicitly, without large negative values of unadjusted winter SST slope more negative than $-0.3^{\circ} \mathrm{C} /$ century the CB would probably not have been noticed.

Acknowledgements: Data were accessed through Climate Explorer (http://climexp.knmi.nl) which was also used to generate correlation maps of local SST changes compared with worldwide SST. ERSST data were also downloaded directly from https://www.ncei.noaa.gov. R. Allan received support from the National Environment Research Council SMURPHS project (NE/N006054/1).

\section{References}

Bacon, S., Reverdin, G., Rigor, I. and Snaith, H.M. (2002) A freshwater jet on the east Greenland shelf. J. Geophys. Res. 107, C7 3608 doi:10.1029/2001JC000935.

Caesar, L., Rahmstorf, S., Robinson, A., Feulner, G. and Saba, V. (2018) Observed fingerprint of a weakening Atlantic Ocean overturning circulation. Nature 556, 191-196. doi.org/10.1038/s41586-018-0006-5.

Chan, D., Kent, E.C., Berry, D.I. and Huybers, P. (2019) Correcting datasets leads to more homogeneous earlytwentieth century sea surface warming. Nature 571, 393-397. doi.org/10.1038/s41586-019-1349-2

Desbruyères, D. Mercier, H., Maze, G. \& D. (2019). Surface predictor of overturning circulation and heat content change in the subpolar North Atlantic. Ocean Science. 15, 809-817. doi:10.5194/os-15-809-2019.

Drijfhout, S., van Oldenborgh, G.J. and Cimatoribus, A. (2012) Is a decline of AMOC causing the warming hole above the North Atlantic in observed and modelled warming patterns? J. Climate 25, 8373-8379 doi: 10.1175/JCLI-D-12-00490.1

Duchez, A., Frajka-Williams, E., Josey, S.A., Evans, D.G., Grist, J.P., Marsh, R., McCarthy, G.D., Sinha, B., Berry, D.I and Hirschi, J.J-M. (2016). Drivers of exceptionally cold North Atlantic Ocean temperatures and their link to the 2015 European heat wave. Environ. Res. Lett. 11,1-9. doi:10.1088/1748-9326/11/7/074004. 
Flatau, M.K., Talley, L. \& Niiler, P.P. 2003. The North Atlantic Oscillation, surface current velocities, and SST changes in the subpolar North Atlantic. J. Climate. 16:2355-2369. doi:10.1175/2787.1

Fratantoni, D. M. (2001), North Atlantic surface circulation during the 1990's observed with satellite-tracked drifters, J. Geophys. Res., 106 (C10), 22067- 22093. doi: $\underline{10.1029 / 2000 J C 000730}$

Good, S. A., M. J. Martin and N. A. Rayner, 2013: EN4: Quality controlled ocean temperature and salinity profiles and monthly objective analyses with uncertainty estimates. Journal of Geophysical Research, 118, 6704-6716, doi: 10.1002/2013JC009067.

Hansen, J., R. Ruedy, M. Sato, and K. Lo (2010), Global surface temperature change. Rev. Geophys., 48, RG4004, doi:10.1029/2010RG000345. 1.

Harden, B. \& Straneo, F. \& Sutherland, D. (2014). Moored observations of synoptic and seasonal variability in the East Greenland Coastal Current. Journal of Geophysical Research: Oceans. 119. 10.1002/2014JC010134.

Huang, B., Thorne, P.W., Banzon, V.F., Boyer, T, Chepurin, G., Lawrimore, J.H., Menne, M.J., Smith, T.M. et al. (2017) Extended reconstructed sea surface temperature, version 5 (ERSSTv5): upgrades, validations, and intercomparisons. J. Climate 30, 8179-8205 doi.org/10.1175/JCLI-D-16-0836.1.

Holliday, N.P., Meyer,A., Bacon, S. Alderson, S.G. and de Cuevas, B. (2007). Retroflection of part of the east Greenland current at Cape Farewell. J. Geophys Res. Oceans 119, 3967-3987 doi:10.1029/2006GL029085.

Josey, S. A., Hirschi, J.J-M., Sinha, B., Duchez, A., Grist, J.P. and Marsh, R. (2018). The recent Atlantic cold anomaly: causes, consequences and related phenomena. Annual Review of Marine Sci. 10, 10 (1). $475-501$. doi:10.1146/annurev-marine-121916-063102.

M. Latif, T. Park and W. Park, 2019: Decadal Atlantic Meridional Overturning Circulation slowing events in a climate model. Climate Dynamics, 53, 1111-1124, doi: 10.1007/s00382-019-04772-7.

Lin,P., Pickart,R.S. \& Daniel, J. Evolution of the Freshwater Coastal Current at the Southern Tip of Greenland J. Physical Oceanog., 48,(9) 2127-2140. doi: 10.1175/JPO-D-18-0035.1

Luo B, D Luo, L Wu, L Zhong \& I Simmonds (2017) Atmospheric circulation patterns which promote winter Arctic sea ice decline, Environ. Res. Lett. 12 054017, doi:10.1088/1748-9326/aa69d0.

Ossó, A., Sutton, R., Shaffrey, L. and Dong, B. (2018). Observational evidence of European summer weather patterns predictable from spring. Proc. Nat. Acad. Sci 115(1) 59-63. doi: 10.1073/pnas.1713146114.

Pickart, R.S., Spall, M.A., Ribergaard, M.H., Moore, G.W., Milliff, R.F. (2003) Deep convection in the Irminger Sea forced by the Greenland tip jet. Nature.424(6945) 152-6.doi:10.1038/nature01729.

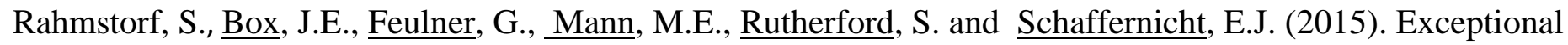
twentieth-century slowdown in Atlantic Ocean overturning circulation. Nature Clim. Change 5, 475-480. doi: 10.1038/nclimate2554.

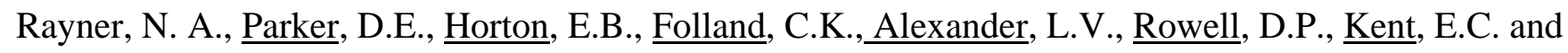
Kaplan, A. (2003) J. Geophys. Res. 108, D14, 4407, Global analyses of sea surface temperature, sea ice, and night marine air temperature since the late nineteenth century. doi:10.1029/2002JD002670, 2003. 
Robson, J., Sutton, R.T., Archibald, A., Cooper, F., Christensen, M., Gray, L.J., Holliday,N.P., Macintosh,C. et al. (2018) Recent multivariate changes in the North Atlantic climate system, with a focus on 2005-2016. International Journal of Climatology 38(14) 5050-5076. doi.org/10.1002/joc.5815

Screen, J.A. \& Simmonds, I. (2010) The central role of diminishing sea ice in recent Arctic temperature amplification. Nature 464, 1334-1350. doi:10.1038/nature09051.

Siler, N., Roe, G.H. and Armour, K.C. (2018). Insights into the zonal-mean response of the hydrologic cycle to global warming from a diffusive energy balance model. J. Climate. 31(8) 7481-7493.

doi.org/10.1175/JCLI-D-18-0081.1.

Simmonds, I. (2015) Comparing and contrasting the behaviour of Arctic and Antarctic sea ice over the 35-year period 1979-2013. Ann. Glaciol., 56(69), 18-28, doi: 10.3189/2015AoG69A909.

Simmonds (2018): What causes extreme hot days in Europe? Env. Res. Lett., 13, 071001, doi: 10.1088/17489326/aacc78.

Stuecker, M. F., Bitz, C. M., Armour, K. C., Proistosescu, C., Kang, S. M., Xie, S. P., Jin, F. F. (2018). Polar amplification dominated by local forcing and feedbacks. Nature Climate Change, 8(12), 1076-1081. https://doi.org/10.1038/s41558-018-0339-y.

Su,Z. (2017): Preconditioning of Antarctic maximum sea-ice extent by upper-ocean stratification on a seasonal timescale. Geophys. Res. Letter, 44, 6307-6315. doi:10.1002/2017GL073236.

Su, Z., Wang, J., Klein, P., Thompson, A. F. and Menemenlis, D. (2018) Ocean submesoscales as a key component of the global heat budget. Nature Commun., 9, 775. doi:10.1038/s41467-018-02983-w.

Sunby, S. \& Drinkwater,K. (2007) On the mechanisms behind salinity anomaly signals of the northern North Atlantic. Progress in Oceanography 73 (2007) 190-202. doi:10.1016/j.pocean.2007.02.002.

Suo, L., Gao, Y., Guo, D. and Bethke. I. (2017) Sea-ice free Arctic contributes to the projected warming minimum in the North Atlantic. Env. Res. Lett., 12, 074004, 1-8. doi:org/10.1088/1748-9326/aa6a5e.

Sutherland, D. \& Pickart, R. (2008). The East Greenland Coastal Current: Structure, variability, and forcing. Prog. Oceanog. 78, 58-77. doi:10.1016/j.pocean.2007.09.006.

Trenberth, K.E., P.D. Jones, P. Ambenje, R. Bojariu, D. Easterling, A. Klein Tank, D. Parker, F. Rahimzadeh, et al. (2007): Observations: Surface and Atmospheric Climate Change. In: Climate Change 2007: The Physical Science Basis. Contribution of Working Group I to the Fourth Assessment Report of the Intergovernmental Panel on Climate Change [Solomon, S., D. Qin, M. Manning, Z. Chen, M. Marquis, K.B. Averyt, M. Tignor and H.L. Miller (eds.)]. Cambridge University Press, Cambridge, United Kingdom and New York.

Våge, K., Spengler, T., Davies, H. W and Pickart, R.S. (2009)Multi-event analysis of the westerly Greenland tip jet based upon 45 winters in ERA-40. QJ Roy. Meteorol. Soc 135, 1999-2011. doi:10.1002/qi.488.

Yang, H. \& Tung, K. K. (1998) J. Clim. 11, 2686-97.

doi: $10.1175 / 1520-0442(1998) 011<2686:$ WVSTAT $>2.0 . C O ; 2$ 